\title{
RESISTÊNCIA MECÂNICA RESIDUAL DE BLOCOS DE CONCRETO E ARGAMASSA DE ASSENTAMENTO UTILIZADOS EM ALVENARIA ESTRUTURAL EXPOSTOS A ELEVADAS TEMPERATURAS.
}

\author{
Gabriel de F. Santos*, Armando L. M. Junior (orientador), Luciano Passos.
}

\section{Resumo}

Embora a alvenaria estrutural seja uma técnica construtiva empregada amplamente em edificações brasileiras, estudos acerca dos efeitos de situações de incêndio sobre este tipo de estrutura ainda são incipientes no cenário nacional. Além disso, também é insuficiente a normatização brasileira sobre o dimensionamento de edificações em alvenaria estrutural para casos de exposição à elevadas temperaturas e, por tal motivo, segue-se normas reconhecidas internacionalmente, as quais podem não ser totalmente adequadas à realidade local. Por isso, esta pesquisa busca analisar as condições mecânicas residuais de elementos constituintes da alvenaria estrutural, mais especificamente, estudando as variações da resistência a compressão e do módulo de elasticidade em função da temperatura de blocos de concreto e corpos de prova de argamassa. Com isso, espera-se contribuir para a ampliação do conhecimento técnico e de dados experimentais sobre o tema para embasar uma normatização nacional de dimensionamento de edificações em alvenaria estrutural de acordo com o crítério de resistência ao fogo.

\section{Palavras-chave:}

\section{Alvenaria Estrutural, Incêndio, Resistência Mecânica.}

\section{Introdução}

Entre as alternativas para contornar a falta de conhecimento sobre o comportamento de estruturas em situações de incêndio está a análise experimental individual de seus elementos componentes. No caso da alvenaria estrutural, os dois elementos mais solicitados por esforços são os blocos e a argamassa de assentamento. Por isso, tais componentes foram os escolhidos para a análise de resistência mecânica residual.

Os dois parâmetros escolhidos para a análise foram a resistência à compressão simples, utilizado para cálculos estruturais em termos do Estado Limite Último, e o módulo de elasticidade longitudinal, fundamental para análises do Estado Limite de Serviço pelas deformações.

\section{Resultados e Discussão}

Os blocos utilizados são de concreto, em geometria 19x19×39 cm e na classe de resistência nominal de 4,5 MPa. Já a argamassa foi ensaiada com corpos de prova cilíndricos com $10 \mathrm{~cm}$ de altura e $5 \mathrm{~cm}$ de diâmetro e em dois traços: (1) $1: 1,6: 7,9$ e (2) $1: 0,5: 6$, ambos expressos pela relação em massa entre cimento, cal e areia, respectivamente.

Como visto nos gráficos, obtidos por meio da ruptura dos corpos de prova e blocos após aquecimento, tanto nos blocos quanto nos corpos de prova, o módulo de elasticidade sofreu pouca variação até $100^{\circ} \mathrm{C}$, mas a partir de $200^{\circ} \mathrm{C}$ houve uma redução aproximadamente linear, provavelmente devido à desidratação dos corpos de prova e blocos, tornando-os menos resistentes a deformação.

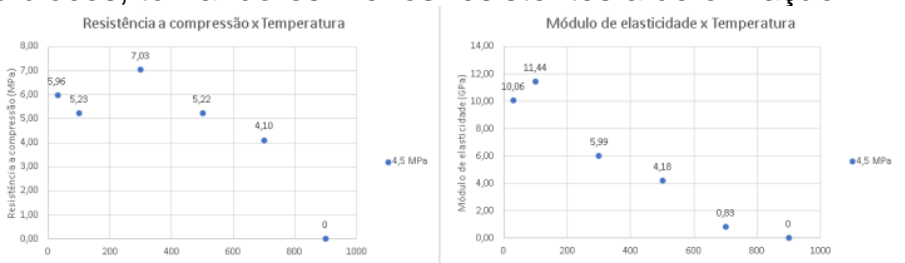

Figura 1. Curvas de resistência à compressão e módulo de elasticidade em função da temperatura dos blocos de concreto.
Além disso, também observa-se que a resistência a compressão da argamassa permanece praticamente constante até $200^{\circ} \mathrm{C}$ e decresce exponencialmente até $500^{\circ} \mathrm{C}$, temperatura na qual há redução significativa. Um fenômeno provavelmente relacionado a esta queda brusca está na reação expansiva da cal exposta a elevadas temperaturas, gerando trincas e diminuindo a resistência a compressão.

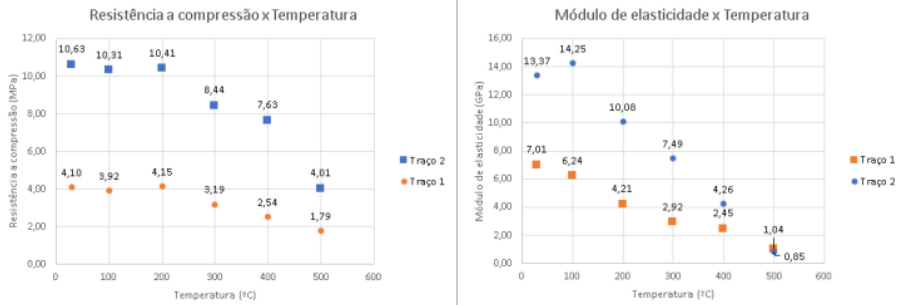

Figura 2. Curvas de resistência a compressão e módulo de elasticidade em função da temperatura dos corpos de prova de argamassa.

Já nos blocos, por outro lado, é observado um aumento inicial da resistência até $300^{\circ} \mathrm{C}$, provavelmente consequência da cura térmica dos compostos cimentantes. Porém, a partir de $500^{\circ} \mathrm{C}$, a resistência decresce e, em $900^{\circ} \mathrm{C}$, é praticamente nula.

\section{Conclusões}

Portanto, com tais dados experimentais, obtidos pela análise dos elementos constituintes de edificações em alvenaria estrutural, espera-se contribuir para futuros estudos complementares que, analisados conjuntamente, viabilizem uma normatização nacional para 0 dimensionamento de alvenaria estrutural em situação de incêndio.

\section{Agradecimentos}

Ao PIBIC-CNPq, pela bolsa para a iniciação científica, e às empresas Tatu e Votorantim, pelo fornecimento dos materiais utilizados nos ensaios.

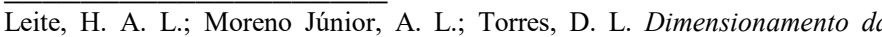
alvenaria estrutural em situação de incêndio: contribuição à futura normatização nacional. Ambiente Construído, Porto Alegre, v. 16, n. 2, p. 89 107, abr./jun. 2016. 